\title{
A Prospective Drug Utilisation Study and Pharmacoeconomic Analysis in Paediatric Dentistry at a Tertiary Hospital
}

\section{Binaya Shrestha' ${ }^{1}$ and Megha Pradhan ${ }^{2}$}

${ }^{1}$ Department of Pharmacology, Kathmandu Medical College Teaching Hospital, Duwakot, Kathmandu, Nepal

${ }^{2}$ Department of Pedodontics, Kathmandu Medical College Teaching Hospital, Duwakot, Kathmandu, Nepal

\begin{abstract}
Introduction: Paediatric dentistry is the branch of dentistry dealing with children from birth to adolescence. Children tend to suffer from various dental conditions which can be primarily infective in nature and hence requires drugs that can be expensive. Drug utilisation data are needed for developing and monitoring policies because data on drug expenditure are not sufficient.

Methods: This was a prospective cross-sectional study conducted in the Department of Pedodontics (paediatric dentistry) of a tertiary care teaching institute in Kathmandu, Nepal from July 2019 to December 2019. During the study period a total of 200 prescriptions were collected. Analysis was conducted using MS excel 2016 and further required analysis was done using Statistical Package for the Social Sciences v22.0.

Results: A total of 200 prescriptions were analysed during the study period, of which 126 were males whereas 74 were females. The most common drug prescribed was paracetamol whereas amoxicillin was the most commonly prescribed antibiotics. Most common condition was periapical abscess but space infection was the most expensive condition. There was no statistically significance between the cost of drugs prescribed for the male and female patients.

Conclusions: The drug prescription pattern was found to be rational. Every institution must have their own Drugs and Therapeutics Committee as has been suggested by WHO, so that patients will be benefited through decreasing economical burden, and adverse drug reactions and that by this, therapeutic effect will be increased.
\end{abstract}

Key words: antimicrobial; drug cost; pedodontics; rational drug use

Correspondence: Binaya Shrestha, Department of Pharmacology, Kathmandu Medical College Teaching Hospital, Duwakot, Kathmandu, Nepal. E-mail: binaya110@yahoo.co.uk

DOI: http://dx.doi.org/10.3126/mjsbh.v19i2.27735

Submitted on: $2020-02-16$

Accepted on: 2020-04-09

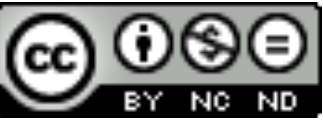

This work is licensed under creative common license:

http://creativecommons.org/licenses/by-nc-nd/4.0/ C MJSBH 2020 


\section{INTRODUCTION}

Paediatric dentistry (Pedodontics) is a branch of dentistry dealing with children from birth to adolescence. In Paediatric Dentistry or Pedodontics, patients require varieties of medicines such as antibiotics, analgesics and antiinflammatory agents. Drug utilisation data are needed for developing and monitoring policies because data on drug expenditure are not sufficient. ${ }^{1}$

Drug utilisation study was defined by WHO as "the marketing, distribution, prescription, and use of drugs in a society, with special emphasis on the resulting medical, social and economic consequences" (WHO, 2003). ${ }^{2}$ Pharmacoeconomics refers to the scientific discipline that compares the value of one pharmaceutical drug or drug therapy to another. It evaluates the cost (expressed in monetary terms) and effects (expressed in terms of monetary value, efficacy or enhancement) of a pharmaceutical product. Since then, a number of other terms have come into use and it is important to understand the interrelationships of the different domains, epidemiology, pharmacoepidemiology, pharmacovigilance, and pharmacoeconomics.

An estimate of around $30 \%-40 \%$ of total health budget of the third world countries is spent on drugs, some of which are useless and expensive and doubles their expenditure on drugs every four years while gross national product doubles every sixteen years. ${ }^{4}$ Epidemiological evaluation of drug utilisation studies in dental paediatric population is limited. So, it is important to assess the drug utilisation pattern for clinical, educational and economic purposes by which the ultimate goal of achieving rational and cost effective dental care. Dental treatment in developing countries is often considered as an expensive treatment and hence people often pay less attention in maintaining a proper dental heath. Hence this study was conducted to pool the data on drug utilisation pattern and pharmacoeconomic analysis of drugs used in paediatric dentistry.

\section{METHODS}

This was a prospective cross-sectional study conducted in the Department of Pedodontics of a tertiary care teaching institute in Kathmandu, Nepal from July 2019 to December 2019. During the study period, a total of 200 prescriptions were collected on random basis. Patients of both sexes were included in the study. The patients who were unwilling to participate in the study were excluded from the study. Prescriptions were collected irrespective of the indications. The data were collected in a proforma, containing information regarding age and sex of the patients as well as type of the drugs used, numbers of drugs prescribed, their dosage, frequency, route of administration, duration of therapy along with the clinical diagnosis. After noting down the required parameters, prescriptions were returned to the patients. The data was not disclosed to any other person besides the co investigator.

The drug treatment cost was calculated by multiplying the cost of each drug dosage unit by the administered daily dose by the number of treatment days. The cost of the drug dose unit was obtained from Nepalese Innovation of Drug and Disease, Current Index of Medical Specialties (CIMS) and the hospital pharmacy were also visited for the price of the drugs. Approval from the Institutional review committee was obtained prior to conduct the study. The raw data was entered in MS Excel and for further required analysis was done using Statistical Package for the Social Sciences v22.0. The data was presented as frequencies, percentages along with appropriate charts. Student's t-test was used and $p$ value $<0.05$ was considered statistically significant.

\section{RESULTS}

Out of 200 prescriptions analysed during the study period, 126 prescriptions were of males whereas 74 prescriptions were of females. The most common drug prescribed was paracetamol. Among the antibiotics, amoxicillin was the most commonly prescribed one. Fixed dose combinations like amoxicillin - clavulinic acid and paracetamol ibubrofen were also prescribed. Oral route was the most frequently used for drugs administration (98.89\%) while $1.11 \%$ of the drugs were prescribed topically. The drugs were found to be prescribed for one to seven days, as shown in Table 3.

Total cost of drugs was NPR (Nepalese Rupees) 26816.99 out of which antibiotic accounted for $74.80 \%$ as shown in Figure 1. 
Table 1. Commonly prescribed drug groups

\begin{tabular}{|l|r|r|}
\hline Drug group & Frequency & \multicolumn{1}{c|}{$\%$} \\
\hline Antimcrobials & & \\
Amoxicillin & 84 & 23.14 \\
Amoxicillin clavulinic acid & 11 & 3.03 \\
$\quad$ Metronidazole & 82 & 22.58 \\
NSAIDS & & \\
$\quad$ Paracetamol & 162 & 45.17 \\
Paracetamol+ibubrofen & 20 & 5.50 \\
Anitivirals & & \\
Acyclovir & 1 & 0.27 \\
Others & 3 & 0.82 \\
\hline
\end{tabular}

There was no statistically significant difference between the cost of drugs between the male and female patients ( $\mathrm{p}$ value $>0.05$ ) as shown in table 4. Space infection was the costliest dental condition that was encountered and periapical abscess was the most common condition.

\section{DISCUSSION}

A proper diagnosis of a dental condition and its management with rational drug and dental procedure plays a pivotal role in paediatric dental care. Drug utilisation studies and pharmacoeconomics are useful for obtaining information about drug use patterns and for identifying high cost drugs. ${ }^{6}$ In this current study the cost of antimicrobial agents have accounted for $74.80 \%$ of the total cost of drugs prescribed. Hence, cost-minimisation studies should be done so that antimicrobials, which are showing similar efficacy

Table 3. Three commonest drugs prescribed with their dose, dosage form, frequency and duration

\begin{tabular}{|c|c|c|c|}
\hline Drugs & $\begin{array}{l}\text { Dose and } \\
\text { dosage form }\end{array}$ & Frequency & Duration \\
\hline Paracetamol & $\begin{array}{l}1 / 2 \text { tab }-1 \text { tab } \\
(250 \mathrm{mg}-500 \\
\mathrm{mg}) \\
4-10 \mathrm{ml}\end{array}$ & $\begin{array}{l}\text { Three times } \\
\text { in a day }\end{array}$ & 1-5 days \\
\hline Amoxicillin & $\begin{array}{l}\text { Cap } 250 \mathrm{mg} \\
5-10 \mathrm{ml}\end{array}$ & $\begin{array}{l}\text { Three times } \\
\text { in a day }\end{array}$ & 2-7 days \\
\hline $\begin{array}{l}\text { Metro- } \\
\text { nidazole }\end{array}$ & $\begin{array}{l}\text { Tab } 200 \mathrm{mg} \\
4-10 \mathrm{ml}\end{array}$ & $\begin{array}{l}\text { Three times } \\
\text { in a day }\end{array}$ & 3-7 day \\
\hline
\end{tabular}

Table 2. Commonly encountered routes of drug administration

\begin{tabular}{|l|r|r|}
\hline Route of administration & Frequency & \multicolumn{1}{c}{$\%$} \\
\hline Oral & 359 & 98.89 \\
Topical & 4 & 1.11 \\
\hline
\end{tabular}

and low cost, should be incorporated into the treatment of dental conditions. ${ }^{7}$ In the current study amoxicillin (23.14\%) was found to be the commonly prescribed antimicrobials which is similar to the study conducted by Jayanthi et al. where the frequency of amoxicillin prescribed was $27.5 \%{ }^{8}$ According to another study Tanwir et al. amoxicillin along with metronidazole were the most prescribed antimicrobials which is similar to the current study. ${ }^{9}$ Antimicrobials are also commonly used in dentistry for prophylactic as well as therapeutic purposes. Two main reasons for its use in paediatric dentistry are control of oral infection and prevention of the sub-acute bacterial endocarditis. ${ }^{11}$ Present study showed that most commonly used fixed dose combinations were ibuprofen and paracetamol which is similar to the study conducted by Sharma et al. ${ }^{12}$

Oral route was the most frequently used for drugs administration $(98.89 \%)$ which is similar to the study conducted by Raducane et al. where the frequency of oral route was found to be $95.2 \%$. In a similar study conducted by Sharma et al the most frequently prescribed drugs were NSAIDS (43.8\%) which is similar to our study where the frequency of NSAIDS prescribed were $50.67 \% .{ }^{10}$ However in this study paracetamol was the commonly prescribed NSAIDS which is different from the study conducted in Western Nepal where ibuprofen

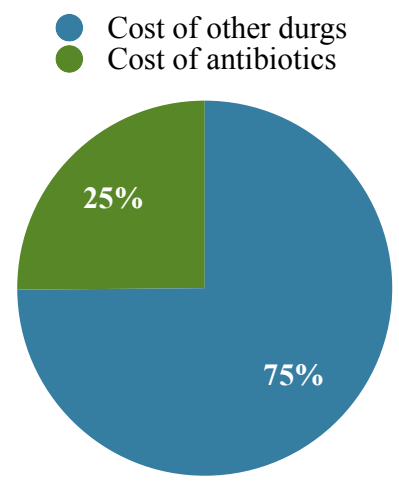

Figure 1. Cost of antibiotics and other drugs shown in percentages 
Table 4. Mean cost of the drugs prescribed

\begin{tabular}{|l|r|r|r|}
\hline Gender & $\begin{array}{l}\text { Number of } \\
\text { prescriptions }\end{array}$ & $\begin{array}{c}\text { Mean cost of } \\
\text { drugs (NPR) }\end{array}$ & $\begin{array}{c}\text { p } \\
\text { value }\end{array}$ \\
\hline Male & 126 & 138.71 & 0.72 \\
Female & 74 & 130.46 & \\
\hline
\end{tabular}

was the most prescribed NSAIDS. This may be due to the difference in the prescribing nature of the local dental professionals. ${ }^{13}$ In the present study male predominated $(n=126)$ in the group of paediatric patients who visited our department during six months, as well as in the patients' group who received medications. These findings are similar to study conducted by Paudel et al. ${ }^{14}$

Periapical abscess was found to be commonest diagnosis and space infection was the costliest condition. This is also another reason for antimicrobials being the major prescribed group. Although amoxicillin plus clavulanic acid has higher antimicrobial activity, in our study only amoxicillin has been prescribed more frequently which has even reduced the cost of drugs. In the study, it was observed that there was no statistical significance between the cost of drugs for male and female patients which may be due to the similarity of the drugs prescribed to both male and female patients. According to the study conducted by Saha et al in paediatric population, the total cost of drugs was found to be Indian Rupees 4993.34 which is different from the current study where the total cost of drugs was found to be Nepalese Rupees 26816.99. The difference in the cost of drugs showed the difference between the treatment regimens for dental conditions from other paediatric diseases. ${ }^{15}$

This study showed the total number of single drug prescribed was $329(90.63 \%)$ and fixed drug combinations were $34(9.37 \%)$. This finding is consistent with the findings of the study conducted in North India but in contrast to the study conducted by Garje et al. in Mumbai. ${ }^{16,17}$ This difference may be due to the variation in the dental conditions encountered and the prescribing habits of the dental practitioners in different geographical conditions. In the current study the drug is prescribed for a period of one to seven days which is different from the similar study conducted by Paudel et al. where the drug where prescribed for two to 15 days. This difference in duration may be due to the difference in treatment protocols followed by prescriber. ${ }^{14}$ In this regards, perhaps the cost of treatment can be reduced if the prescribers make a common protocol for similar clinical conditions.

Dental conditions can be treated very effectively by dental therapeutic procedures followed by drug therapy. Nowadays dental practitioners and the patients are flooded with a vast array of pharmaceutical preparations with variation in price. But pharmacoeconomic analysis which can serve as a source of data are limited in resource limited countries like ours. Thus, it is prudent that more such studies need to be conducted on regular basis in such geographical regions of the world. Major health institutions should establish their own drugs and therapeutics committee and formulate their own formulary. This would help the patients of resource limited countries to less financial burden, as well get familiar drugs which would also lead to reduction in adverse drug reactions with the prescribed drugs. ${ }^{18,19}$

\section{CONCLUSIONS}

The drug prescription pattern in paediatric dentistry in our institute was found to be rational. Aantimicrobials were found to be the mainstay in the treatment of paediatric dentistry. Pharmacoeconomic study should be conducted on a regular basis in paediatric dentistry. Every institution must have its own drugs and therapeutics committee as has been suggested by WHO, so that patients will be benefited through decreasing economical burden, and lesser adverse drug reactions leading to increased therapeutic effects.

\section{ACKNOWLEDGEMENTS}

I would like to thank for the co-operation support from the interns and medical officers from the Department of Pedodontics during the study period. 
To cite this article: Shrestha B, Pradhan M. A prospective drug utilisation study and pharmacoeconomic analysis in paediatric dentistry at a tertiary hospital. MJSBH. 2020;19(2):60-4.

Conflict of Interest: None declared

\section{REFERENCES}

1. Mossialos E, Mrazek MF. Data needed for developing and monitoring policies. Int J Risk Safety Med. 2002;15: $15-27$.

2. World Health Organisation (WHO) Collaborating Centre. (2003)Introduction to Drug Utilisation Research. World Health Organisation (WHO). (2009). Medicines use in primary care in developing and transitional countries. Fact book summarising results from studies reported between 1990 and 2006. Geneva: WHO

3. Biswas NR, Biswas RS, Pal PS. Patterns of prescriptions and drug use in two tertiary hospitals in Delhi. Indian J Physiol Pharmacol. 2000;44:109-12. PMID: 10919106

4. Arnold RJG, Ekins S. Time for cooperation in health economics among the modelling community, Pharmaco Economics. 2010;28(8):609-13. DOI: https://doi.org/10.2165/11537580-000000000-00000

5. Chester, B.G. Polypharmacy in elderly patients with diabetes. Diabetes Spectrum. 2002;15(4):240-4. DOI: https:// doi.org/10.2337/diaspect.15.4.240

6. Lamichhane DC, Giri BR, Pathak OK, Panta OB, Shankar PR. Morbidity profile and prescribing patterns among outpatients in a teaching hospital in Western Nepal. MJM. 2006;9(2):126-33. PMID: 18523618

7. Anderson R, Calder L, Thomas DW. Antibiotic prescribing for dental conditions: General medical practitioners and dentists compared. Br Dent J. 2000;188(7):398-400. DOI: https://doi.org/10.1038/sj.bdj.4800493

8. Jayanthi MK, Naidu SV, Drug utilisation pattern and pharmacoeconomic study in paediatric dentistry at a tertiary hospital. Int J Pharm. 2014;6(2):70-72

9. Tanwir F, Marrone G, Tariq A, Lundborg CS. Diagnosis and prescribing pattern of antibiotics and painkillers among dentists. Oral Health Prev Dent. 2015;13(1):75-83. DOI: 10.3290/j.ohpd.a32341

10. Sanz EJ, Boada JN. Drug utilisation by children in Tenerif Island, Spain. Eur J Clin Pharmacol. 1988;34:495-9. DOI: https://doi.org/10.1007/BF01046708

11. Peedikayil FC. Antibiotics: Use and misuse in paediatric dentistry. J Indian Soc Pedod Prev Dent. 2011;29:282-87. DOI: https://doi.org/10.4103/0970-4388.86368

12. Sharma M, Tandon S, Chugh T, Sharma S, Parmod PS, Aggarwal V, et al. Drug Abuse in Paediatric Dentistry: A Cross-Sectional Study. J Clin Diagn Res. 2014;8(3):205-7. DOI: https://doi.org/10.7860/JCDR/2014/7134.4163

13. Das B, Baral P. Analgesic use in dentistry in a tertiary hospital in western Nepal. Pharmaco Epidemiol Drug Saf. 2004;13(10):729-33. DOI: https://doi.org/10.1002/pds.972

14. Paudel KR, Sah NK, Jaiswal AK. Prevalence of pharmacotherapy in the department of paediatric dentistry. Kathmandu Univ Med J. 2010;8(30):190-4. DOI: https://doi.org/10.3126/kumj.v8i2.3556

15. Saha L, Kaur S, Khosla P, Kumari S, Rani A. Pharmacoeconomic Analysis of Drugs Used in the Treatment of Pneumonia in Paediatric Population in a Tertiary Care Hospital in India - A Cost-of-Illness Study. Curr Opin Infect Dis. 2007;20:177-81.

16. Zuppa A, Vijayakumar S, Jayaraman B. An informatics approach to assess pediatric pharmacotherapy: Design and implementation of a hospital drug utilisation system. J Clin Pharmacol. 2007;47:1172-80. DOI:https://doi.org/ $10.1177 / 0091270007304105$

17. Arumugam V, Kothiyal P, Juyal V, Pandey A, Tripathi P. Drug utilisation assessment in asthma therapy through prescription monitoring at Dehradun Hospitals. Ind Allergy Asthma Immunol. 208;2008;22(1);15-8. DOI: https:// doi.org/10.14219/jada.archive.2000.0181

18. Palmer NO, Martin MV, Pealing R, Ireland RS. Paediatric antibiotic prescribing by general dental practitioners in England. Int J Paediatr Dent. 2001;11(4):242-8. DOI: https://doi.org/10.1046/j.1365-263X.2001.00280.x

19. Sancho-Puchades M, Herraez-Vilas JM, Valmaseda-Castellon E, Berini-AytesL, Gay-Escoda C. Analysis of the antibiotic prophylaxis prescribed by Spanish Oral Surgeons. Med Oral Patol Oral Cir Bucal. 2009;14(10):533-7. DOI:https://doi.org/10.4317/medoral.14.e533 